\title{
Evaluation of a Puzzle-based Virtual Platform for Improving Spatial Visualization Skills in Engineering Freshmen
}

\section{Dr. Vimal Kumar Viswanathan, San Jose State University}

Dr. Vimal Viswanathan is an assistant professor in the Mechanical Engineering Department at San Jose State University. His research interests include design theory, design automation, design for $\mathrm{X}$ and engineering education. His engineering education work includes the application of brain-based learning protocols in engineering education, technology-assisted education, problem-based learning, and improving spatial visualization skills.

\section{Sadaqatali Hussainali Mirza, San Jose State University}

I am an MSME student at SJSU, graduating in May 2020. I have previously worked as a mechanical design engineer at a 3D printing company and as an intern at Mahindra \& Mahindra Pvt Ltd. in India.

\section{Dr. Chitra R Nayak, Tuskegee University}

Dr. Nayak joined Tuskegee University as an assistant professor in Physics in 2014. After completing her $\mathrm{Ph} . \mathrm{D}$ (2009) in the area of nonlinear dynamics from Cochin University, India, she worked as a postdoctoral fellow in the interdisciplinary field of bacterial biophysics and immunology at Dalhousie University and University of Toronto, Canada. Her current area of research work includes nonlinear analysis of biosignals and fluid dynamics. Dr. Nayak is also involved in education research at Tuskegee University.

\section{Dr. Maria Calhoun, Tuskegee University}

Dr. Maria Calhoun is an associate professor of mechanical engineering at Tuskegee University. She received her Ph.D. in material science and engineering from Tuskegee University in 2009. She teaches courses in engineering graphics, freshman design, and probability and statistics for engineers. Her research interests include pedagogy development for learning and engagement; first year engineering studies, and nanostructured films and membranes for various applications. 


\title{
Evaluation of a Puzzle-based Virtual Platform for Improving Spatial Visualization Skills in Engineering Freshmen
}

\begin{abstract}
Being able to spatially visualize and mentally rotate is a key skill necessary to succeed in graphics and subsequent engineering courses. Recent research has focused on methods to develop Spatial Visualization (SV) skills in engineering students, as it is a key skill to succeed in most of the STEM fields. However, in most of the engineering schools, the instructors find it very difficult to develop keen SV skills in students. The major factors contributing to this challenge include, but not limited to the huge class sizes, limited time to teach the material, lack of effective demonstrations and the unavailability of feasible hands-on activities. With the funding from the National Science Foundation, the authors are developing a puzzle-based active learning platform called "Student Assistant for Visualization in Engineering" (SAVE) for developing SV skills in engineering freshman. In the preliminary version of this learning platform, the students are asked to complete a quiz with tasks requiring SV skills. For any incorrect answer, they are provided with automated hints about their mistakes. These hints are expected to help them in solving the following tasks. If they commit three mistakes, the quiz locks itself and creates a report on their performance thus far. The students are able to go back and restart the quiz. The student's target is to complete the quiz with a minimum number of attempts. In the study reported here, the effectiveness of this game platform in conveying essential concepts of engineering graphics is investigated. Firstly, SAVE is implemented in a smaller classroom and the student feedback is collected. Then, it is implemented in a freshmen graphics class in a large public university in the west coast. The performance of the participating students in a follow-up exam is compared against that of a control group. The results show that the use of SAVE improves students' conceptual understanding compared to a control group, as measured by the scores in the follow-up exam.
\end{abstract}

\section{Introduction \& Motivation}

Pictorial representation of three-dimensional objects is one of the oldest forms of communication. Sketches and images have been a very popular medium to communicate ideas and to store information for future use. The area that deals with two-dimensional pictorial representations and communication of information is called "graphics" [1]. The area of graphics have been evolved from very crude hand sketches to the currently used formal engineering drawings [2]. For engineers, the graphics language using lines and symbols to represent information has been proved to be more effective than verbal communication [3]. According to Bertoline, Wiebe, Miller, and Mohler [4], 92\% of the communication in engineering is based on graphics whereas the remaining $8 \%$ is shared by verbal and mathematical communication. This popularity itself calls for the inclusion of a well-developed graphics curriculum in our 
engineering schools. In addition, research has shown the role of graphics education in developing well-balanced human citizens $[5,6]$.

Spatial visualization (SV) skill is an essential quality for being able to communicate graphically. Spatial visualization skill can be defined as the ability to mentally understand, visualize, rotate and manipulate geometric objects [1,7-9]. Literature shows that keen SV skills is an indicator of achievement in STEM fields [10]. These skills have been demonstrated as a key factor for the success in 84 careers [11]. In addition, a 2010 report on the role of women in STEM fields identifies that SV skills are important for the success of women students in STEM related fields [12]. The report also states that women and underrepresented minorities in STEM have comparatively lower SV skills.

Development of students' SV skills has been a major challenge in engineering graphics communications courses. This is a hard skill to acquire and the instructional methods being employed have a great effect on the SV skills [12]. This is the major reason for the recent interest in the research community on the methods to improve SV skills and mental rotation abilities in students [1, 12-16]. For example, a recent study recommended the use of tangible models as an effective technique to develop visualization skills [3]. Similarly, Sorby developed a short course on SV skills which has proven to be effective in improving student GPAs in a wide range of STEM courses [16]. This study was conducted at Michigan Tech and the results showed that only $42 \%$ of students in engineering with low SV skills graduated in their major. However, after attending the short SV skill course, the retention rate of students with originally low SV skills increased to $64 \%$ (an increase of 52\%). Currently the materials developed by Sorby [17] have been used widely in the United States [15].

There are multiple factors that influence the engineering graphics instruction at engineering departments. In most engineering schools, graphics is taught as a freshman course and they have comparatively huge class sizes. The unavailability of proper demonstrations and educational technologies to assist in graphics classrooms is a major factor of concern. Mainly the change of spatial dimension between 2-D and 3-D is a confusing factor for many students. When a spatial dimension change and visual rotations are together required to effectively visualize an object, it becomes a hard task for our students. The limited class time is another important factor as the instructor is unable to provide the immediate help that the students need. Since these courses are offered the first semester they attend a university, the students often are not mature enough to admit that they need additional help outside the classroom. Because of the same reason, many of them do not follow up during office or tutoring hours for additional assistance.

In an effort to improve the SV skills of engineering freshmen, the authors employed a rapid feedback cycle [29] based on the mastery approach. In this process, the instructor provides very rapid feedback on assignments (within two working days after submission) and they have an opportunity to resubmit the assignment to gain additional points. During the initial feedback, the mistakes are not completely explained to the students, but hints about their mistakes are 
provided. In a controlled experiment conducted at Tuskegee University, it was observed that the students who resubmitted their work based on the feedback improved their SV skills, as measured by the Purdue Visualization Test (PVT), compared to a group of students who did not. However, this approach requires a significant time investment from the instructor, which is a major drawback.

Building on this previous work, the authors developed a quiz on SV that can provide automated feedback in the form of hints to students. The target is to establish the rapid feedback cycle without the additional time investment from the part of the instructor. Eventually, this platform is expected to be a place where students can go for additional practice and feedback on their work. Currently, SAVE has a quiz format with automated conceptual feedback. This paper reports the pilot implementation of this quiz in two universities and the results from the implementation.

\section{Background}

\section{Repeated Learning Cycles}

Existing literature shows the significance of formative feedback in education [18-22]. Feedback plays a crucial role in motivating the learning process, in addition to its role in acquisition of new knowledge[23, 24]. Formative feedback is defined as the information communicated to a student with the intention of modifying the student's thinking or behavior with respect to the learning. The plethora of literature on formative feedback shows the various dimensions of formative learning and how to implement formative feedback to maximize its benefits. One of the most important dimension that has been extensively studied is the timing of the feedback. While there are conflicting results on this issue (e.g., Kulhavy \& Anderson[25], Surber \& Anderson[26]), many recent studies show that immediate feedback is beneficial to maximize the learning[26-28].

\section{Student Assistant for Visualization in Engineering (SAVE)}

Student Assistant for Visualization in Engineering (SAVE) is a software platform that is being developed for engineering graphics students to provide them real-time quick feedback using a puzzle-based game format. Funded by the National Science Foundation, the SAVE project aims to create a virtual platform where students can achieve mastery of SV skills using a self-paced game-like environment. Currently, the pilot system has a number of quizzes that the students can practice with and the system provides them with tips and hints for their successful completion of those. The system uses a library of questions that is designed to challenge the students at different levels. For each question four choices of answers are created, out of which one is the correct response. The wrong choices are created by incorporating the common mistakes that the students are prone to make. This is done by examining previous midterms and discussion with instructors teaching the course. The desktop version of the quiz is written in c\#.

In SAVE, the students are prompted to login using their institutional credentials. An option to choose the appropriate level of difficulty for the quizzes - easy, medium, and challenging - is 
available through a drop-down menu. Once the student chooses the level of the quiz, he/she will have 30 minutes to complete that particular level. An object is displayed along with a question on the mental rotation and visualization of the object and four choices are displayed. The student can choose an answer. If their choice is correct, the next question is displayed. If he/ she chooses a wrong answer, a hint is provided to indicate what they missed and the next question is displayed. Figure 1 shows the SAVE interface and the various steps in the process, as previously described. If one makes three wrong selections on the same quiz, the quiz exits itself. A report is generated with the feedback and time details at the termination of the quiz.

While creating the wrong choices, they were classified into the following classes based on common mistakes that the students make. Some examples include missing solid lines or hidden lines, correctness of the dimensions, location and dimension of cylindrical or non-rectangular portions, and features of chamfer blocks. These common mistakes are determined using the previous homework assignments and tests and also through discussion with instructors of similar courses.

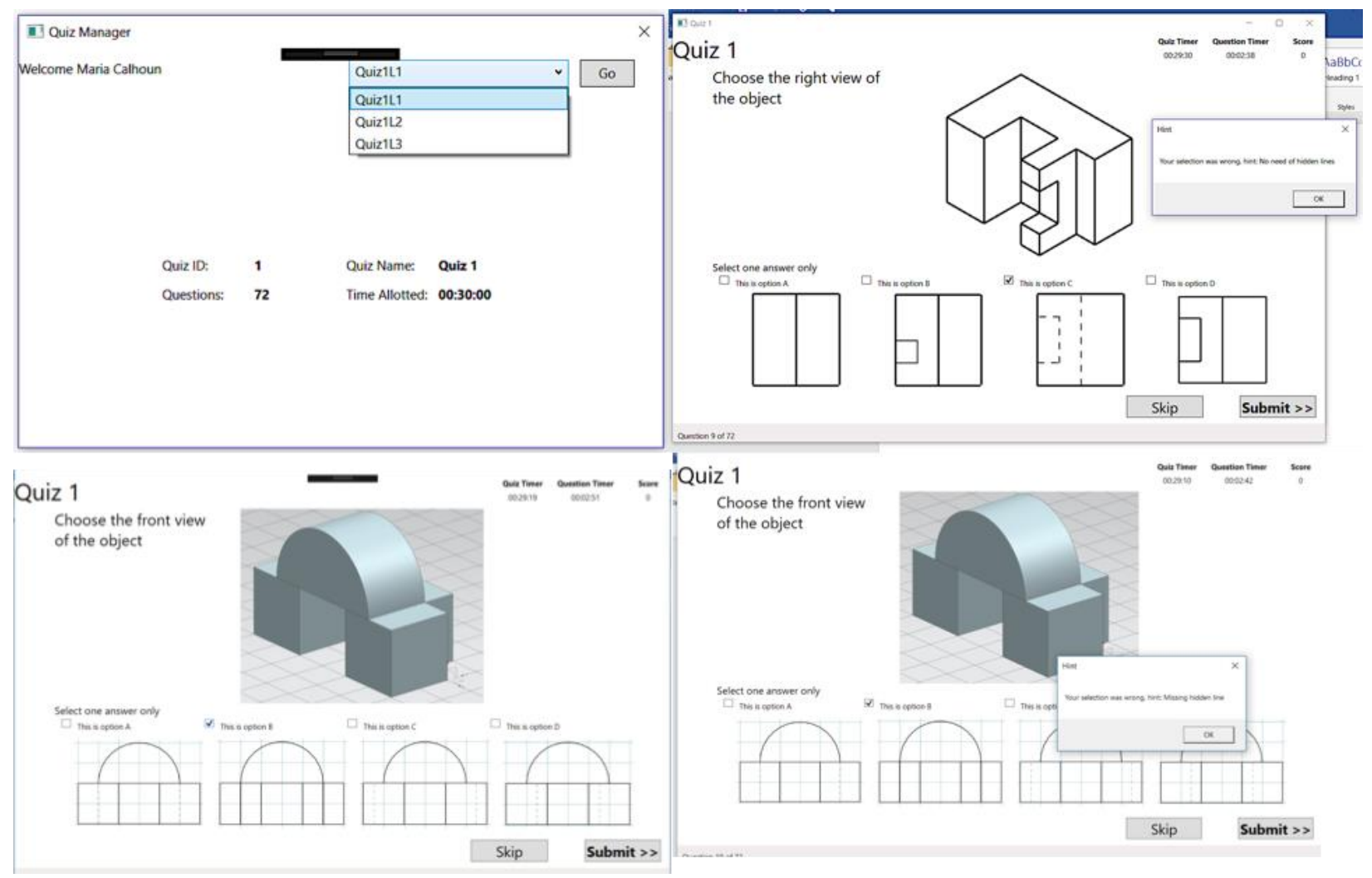

Figure 1. The quiz module with the drop down menu for selection and hints corresponding to two wrong choices 
It is expected that the immediate feedback that the students receive from the SAVE quiz helps them in reviewing their choice and understanding the corresponding concept. This is also expected to help them in avoiding similar mistakes in the subsequent questions.

\section{Research Question}

In the study described here, the authors aim to: (1) collect feedback from students to facilitate further development of SAVE, and (2) to answer the following research question:

Does the rapid feedback in a conceptual pointer format from an online quiz with mental rotation and visualization activities help students in improving their SV skills?

\section{Implementation of SAVE at Tuskegee University}

The first implementation of SAVE was performed at Tuskegee University (TU) where it was developed. TU is a minority institution with a typical class size of around 30 in the freshmen classes. Freshmen in an engineering graphics class were asked to volunteer to evaluate this software. Informed consent, approved by the university's Institutional Review Board (IRB) were provided to the volunteers at the beginning of the experiment. The students who volunteered were given access to SAVE, in addition to their regular learning resources. They were requested to provide a feedback in the form of an exit survey at the end of level 1 of the quiz. The aim was to understand the students' perspective on this platform. The survey asked four questions. The students were asked to rate their take on the usefulness of the platform to learn multiviews, the suitability of the time allotted and the difficulty level of the problems. The fourth question was a descriptive one in which the students were asked to describe any improvements they wished to see in SAVE.

Figure 2 shows the results from the rating questions on the survey. Based on these results, a good majority of the students thought that SAVE helped in understanding the concept of multiviews. A significant percentage of the students agreed that the time available and the difficulty of the problems were adequate. For the improvements they wished to see, many students suggested adding more number of questions and questions with increased difficulty. These were added to the platform. A few students also wished to have the ability to rotate the object provided to them. This capability is currently being added to the platform and its effectiveness will be explored in the future work. 


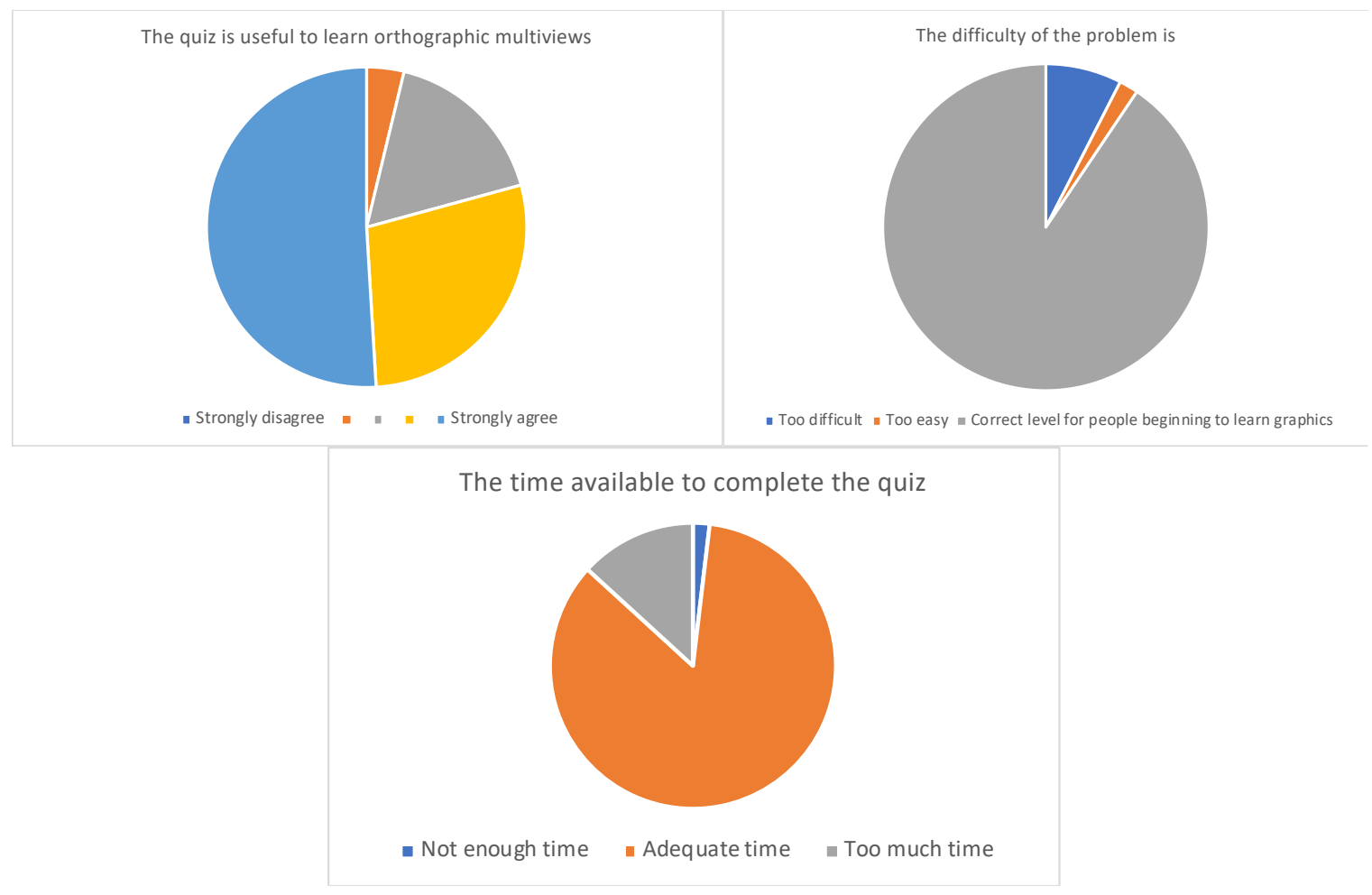

Figure 2. Student ratings for SAVE platform based on exit surveys in TU

\section{Implementation of SAVE at San Jose State University}

In addition to collecting data on the potential improvements on the SAVE platform, this study also aims to investigate the research question proposed earlier. For this investigation, the engineering design graphics class at San Jose State University (SJSU), a large, public, minorityserving university is used. This course has a typical enrolment of about 200 students each semester distributed across six sections. The course deals with multiviews, hand sketching and computer-aided modeling. The last lab section of the semester of this course is used for the study.

\section{Method}

Students in all six sections of this course were requested to volunteer for the study. They were informed that a new puzzle-based platform for teaching graphics concepts was being evaluated and their participation was requested. If they were willing to volunteer, they were required to sign a consent form in electronic format. This consent form was approved by the IRB of the university. If the student was a minor at the time of the experiment, they were required to obtain parental consent, but none of the volunteers met that criteria. Their regular classroom, a computer lab, was used as the study location. SAVE quiz was pre-loaded to the server and the students could start the quiz by opening the software. They were required to sign a consent form before they could participate. The experimental session was considered as an extra assignment 
that could replace their lowest assignment grade. The students were given with the full grade regardless of their answers.

Each of the six sections was assigned to one of the three experimental conditions: (1) "No repeat" condition where the students could not repeat the same quiz after the quiz exits itself upon making three mistakes, (2) "With repeat", where the students could use unlimited attempts to complete the quizzes, and (3) "Control" where participants were instructed to read a couple of chapters from their textbook about multiviews. All the participants were expected to take a follow-up exam that tested their knowledge in multi views. The questions in the exam were taken from their textbook and of the same type and difficulty as in SAVE. Two sections were designated as no repeat, two as with repeat and the remaining two as control.

Though students in all the six sections volunteered to participate, the data from two sections were not collected due to technical issues with the server. Two sections were used for no repeat and one each for with repeat and control conditions. The sample size for each experimental condition is shown in Table 1.

Table 1. The number of lab sessions used and the sample size for each experimental condition

\begin{tabular}{|l|c|c|c|l|}
\hline $\begin{array}{l}\text { Experimental } \\
\text { condition }\end{array}$ & $\begin{array}{l}\text { \# lab } \\
\text { sessions } \\
\text { used }\end{array}$ & $\begin{array}{l}\text { \# lab } \\
\text { sessions } \\
\text { with usable } \\
\text { data }\end{array}$ & $\begin{array}{l}\text { Final } \\
\text { sample } \\
\text { size }\end{array}$ & $\begin{array}{l}\text { Materials } \\
\text { received }\end{array}$ \\
\hline No repeat & 2 & 2 & 41 & $\begin{array}{l}\text { One attempt on } \\
\text { SAVE Quiz, no } \\
\text { reading }\end{array}$ \\
\hline With repeat & 2 & 1 & 22 & $\begin{array}{l}\text { Multiple attempts } \\
\text { on SAVE Quiz, no } \\
\text { reading }\end{array}$ \\
\hline Control & 2 & 1 & 23 & $\begin{array}{l}\text { No SAVE quiz, } \\
\text { reading on } \\
\text { multiviews }\end{array}$ \\
\hline
\end{tabular}

All the sections that participated in the study were part of the same course and the lecture sessions were common. The students received one hour lecture every week followed by a lab session of 2 hours and 45 minutes of length. The lab sessions were taught by TAs. As all the lab sessions completed the same activities throughout the semester, the study participants were not expected to differ in terms of their preparation in CAD.

\section{Procedure}

At the beginning of the experiment, each group received an instruction sheet explaining what they were expected to do. The students were allowed 5 minutes to read the instructions and be 
prepared to start the quiz. Then they were instructed to start the quiz and begin answering the questions. The control group received a copy of two chapters in their textbook that discussed multiviews with a number of visuals. One of the authors was always available to answer any potential questions. Since the group with repeat options could continue working on their problems for a long period of time, the total time for the study was restricted to one hour regardless of their experimental condition. This time limit was found to be sufficient for other experimental conditions as well. Each time SAVE existed itself, it created and autosaved a report on the three mistakes that the student committed. These reports were saved on the server which were later collected by the investigators.

At the end of the SAVE activity, the students were required to take a follow-up exam with 10 questions. All these questions were in a similar format as SAVE, but the exam was taken on paper. The students were allowed to leave the room after they completed the exam. They could also leave the room if they decided to withdraw from the study.

\section{Results}

The results from the follow-up exam given to all participating students is shown in Figure 3. During the follow-up exam, several students complained about a confusion between multiple choices in one question. Hence this question was eliminated from analysis and the scores on the remaining 9 questions were used for the analysis. The maximum possible score in this follow-up exam was 9. It was observed that the students who used SAVE performed better compared to those who did not. Interestingly, the average score of students who were unable to repeat SAVE quizzes was higher than those who could repeat them. The group that repeated SAVE quizzes outperformed their peers in the control group by a very small margin.

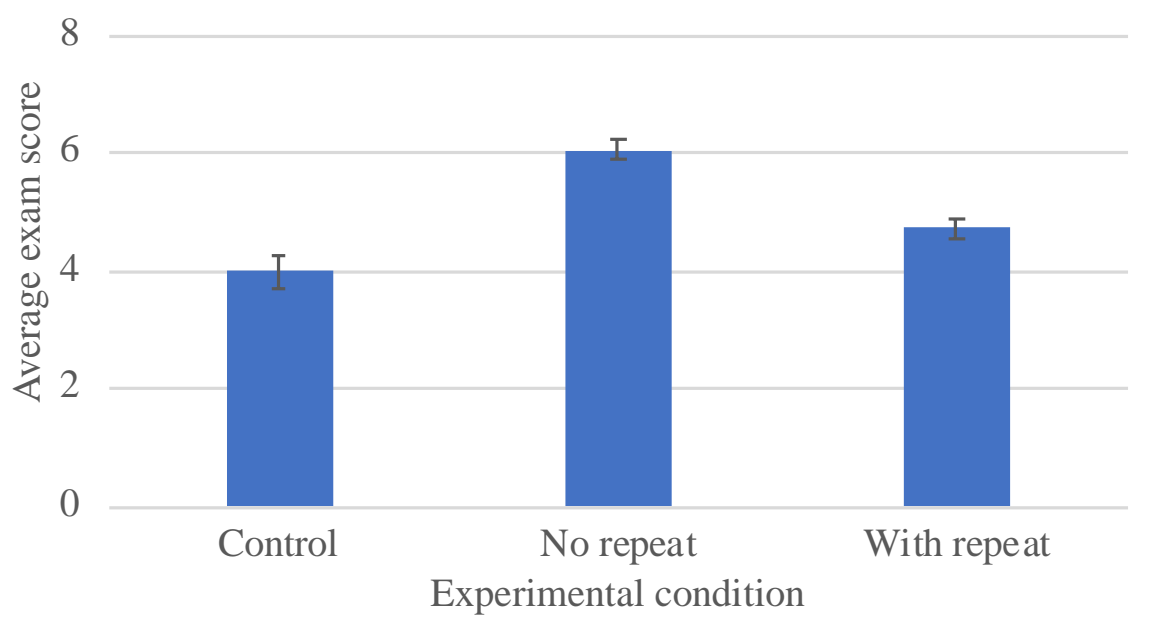

Figure 3. Comparison of follow-up exam scores of all participating students. All the error bars show ( \pm 1$)$ S.E. 
For the statistical comparison, a one-way ANOVA was used. The data satisfied both the normality and homogeneity of variance conditions for performing an ANOVA. The results showed that the performances of the experimental groups were significantly different from each other and the experimental condition affected their performance. A Tukey HSD post-hoc test was used to analyze the data further and the results are shown in Table 2. It was observed that when the students were able to use SAVE without repeating the quizzes, they performed significantly better compared to the control group. The difference between the two groups that used SAVE was also significant, statistically. However, the students who were allowed to repeat SAVE only showed marginal improvement in the SV skills compared to the control, but this difference was statistically insignificant.

Table 2. Results from Tukey HSD post-hoc tests on the data

\begin{tabular}{|c|c|c|}
\hline Conditions compared & p-value & Interpretation \\
\hline Control vs No Repeat & $<0.05$ & Significant \\
\hline Control vs With Repeat & 0.07 & Not significant \\
\hline No Repeat vs With Repeat & $<0.05$ & Significant \\
\hline
\end{tabular}

All comparisons are made with $\alpha=0.05$

Based on the results, it can be concluded that the rapid feedback in the form of small tips that the students obtain from SAVE can help to improve their SV skills, as measured by the follow-up exam. However, when they are allowed to repeat the use of SAVE quizzes, the learning gains are not very significant. Interestingly, it was observed that none of the students who were allowed to repeat reached Quiz 2 within the time allowed for the study. Some of them repeated the questions in Quiz 1 as many as 12 times. It can be argued that while repeating Quiz 1, the students in this group were trying to remember the correct responses and to reproduce them in the following attempt, which minimized their learning gains. These students were focused on scoring $100 \%$ in the quiz rather than understanding the mistakes they made in the previous attempt. They still achieved marginal improvement in their SV skills in the process.

\section{Conclusions}

Motivated by the challenges that engineering graphics instructors face when teaching spatial visualization skills, SAVE project aims to develop a puzzle-based virtual platform where students can gather immediate tips and hints about the work they completed. SAVE hosts a number of questions where students are required to mentally rotate and visualize various shapes. This work in progress paper examines the feedback from users and incorporates that feedback into the SAVE platform. Further, the authors conduct a simple empirical study where they compare the scores in a simple visualization test across three groups of students where two groups are allowed to use SAVE and a control group who is not exposed to SAVE. The 
preliminary results show the students who use SAVE score better in their follow-up exam. This indicates that SAVE has the potential to be a platform where instructors can direct their students to improve their spatial visualization skills.

\section{Future Work}

In addition to continuously improving the SAVE platform, the future work on this project will explore the trends shown by the reports autosaved by SAVE. It will be interesting to explore if students are repeating their mistakes after being given tips to avoid them. It will also be interesting to see how these trends correlate with the lower average scores in the experimental condition where participants are allowed to repeat SAVE quizzes. The future work will also explore if these results are repeatable at other universities.

\section{Limitations of the Study}

In this study, the prior exposure of the participants to sketching and CAD modeling packages is not explored. In the student population in SJSU, it is typical that around $10 \%$ of the students in the design graphics class possess some extent of CAD training. However, this is not expected to significantly bias the results. This factor will be explored in future studies.

\section{Acknowledgements}

Partial support for the work is provided by the National Science Foundation grant number DUE1611763. Any opinions, findings, and conclusions or recommendations expressed in this paper are those of the authors and do not necessarily reflect the views of the National Science Foundation. The authors would also like to thank Prof. Ken Youssefi, instructor for ME 20 course, for his support in conducting the study at San Jose State University.

\section{References}

[1] J. V. Ernst, D. Lane, and A. C. Clark, "Pictorial Visual Rotation Ability of Engineering Design Graphics Students," presented at the ASEE Annual Conference, Indianapolis, IN, 2014.

[2] R. P. Springer, C. H. Dobrovolny, and J. S. Hoelscher, Graphics for Engineers, Visualization, Communication and Design: John Wiley \& Sons, 1968.

[3] S. A. Scribner and M. A. Anderson, "Novice drafters' spatial visualization development: Influence of instructional methods and individual learning styles," 2005.

[4] G. R. Bertoline, E. N. Wiebe, C. L. Miller, and J. L. Mohler, Technical graphics communication: Irwin, 1995.

[5] X. Danos, "Curriculum Planning for the Development of Graphicacy," Design and Technology Education: an International Journal, vol. 18, 2013.

[6] E. Fry, "Graphical literacy," Journal of Reading, pp. 383-389, 1981.

[7] G. P. Adanez and A. D. Velasco, "Predicting academic success of engineering students in technical drawing from visualization test scores," Journal of Geometry and Graphics, vol. 6, pp. 99-109, 2002. 
[8] C. L. Miller and G. R. Bertoline, "Spatial Visualization Research and Theories: Their Importance in the Development of an Engineering and Technical Design Graphics Curriculum Model," Engineering Design Graphics Journal, vol. 55, pp. 5-14, 1991.

[9] W. F. Kelly Jr, "Spatial Ability Measurement in an Introductory Graphic Communications Course."

[10] D. H. Uttal, N. G. Meadow, E. Tipton, L. L. Hand, A. R. Alden, C. Warren, et al., "The malleability of spatial skills: a meta-analysis of training studies," Psychological bulletin, vol. 139, p. 352, 2013.

[11] I. M. Smith, Spatial ability: Its educational and social significance: RR Knapp, 1964.

[12] C. Hill, C. Corbett, and A. St Rose, Why So Few? Women in Science, Technology, Engineering, and Mathematics: ERIC, 2010.

[13] D. I. Miller and D. F. Halpern, "Can spatial training improve long-term outcomes for gifted STEM undergraduates?," Learning and Individual Differences, vol. 26, pp. 141$152,2013$.

[14] G. Marunic and V. Glazar, "Spatial ability through engineering graphics education," International Journal of Technology and Design Education, vol. 23, pp. 703-715, 2013.

[15] L. V. D. Einde and N. Delson, "Using Touch Interface Technology for Spatial Visualization Training," presented at the ASEE Annual Conference, Indianapolis, IN, 2014.

[16] S. A. Sorby and N. Veurink, "Long-term Results from Spatial Skills Intervention among First-Year Engineering Students," in Proceedings of the 65th Midyear Meeting of the Engineering Design Graphics Division of ASEE, 2010.

[17] S. A. Sorby, Developing Spatial Thinking Workbook, 1 ed. Independence, KY: Cengage Learning, 2011.

[18] R. Azevedo and R. M. Bernard, "A meta-analysis of the effects of feedback in computerbased instruction," Journal of Educational Computing Research, vol. 13, pp. 111-127, 1995.

[19] R. L. Bangert-Drowns, C.-L. C. Kulik, J. A. Kulik, and M. Morgan, "The instructional effect of feedback in test-like events," Review of educational research, vol. 61, pp. 213238, 1991.

[20] A. Corbett and J. R. Anderson, "Feedback timing and student control in the LISP Intelligent Tutoring System," in Proceedings of the Fourth International Conference on AI and Education, 1989, pp. 64-72.

[21] M. L. Epstein, A. D. Lazarus, T. B. Calvano, K. A. Matthews, R. A. Hendel, B. B. Epstein, et al., "Immediate feedback assessment technique promotes learning and corrects inaccurate first responses," The Psychological Record, vol. 52, p. 5, 2010.

[22] D. R. Pridemore and J. D. Klein, "Control of practice and level of feedback in computerbased instruction," Contemporary Educational Psychology, vol. 20, pp. 444-450, 1995.

[23] M. R. Lepper and R. W. Chabay, "Intrinsic motivation and instruction: Conflicting views on the role of motivational processes in computer-based education," Educational Psychologist, vol. 20, pp. 217-230, 1985.

[24] S. Narciss and K. Huth, "How to design informative tutoring feedback for multimedia learning," Instructional design for multimedia learning, vol. 181195, 2004.

[25] R. W. Kulhavy and R. C. Anderson, "Delay-retention effect with multiple-choice tests," Journal of Educational Psychology, vol. 63, p. 505, 1972. 
[26] J. R. Surber and R. C. Anderson, "Delay-retention effect in natural classroom settings," Journal of Educational Psychology, vol. 67, p. 170, 1975.

[27] A. T. Corbett and J. R. Anderson, "Locus of feedback control in computer-based tutoring: Impact on learning rate, achievement and attitudes," in Proceedings of the SIGCHI conference on Human factors in computing systems, 2001, pp. 245-252.

[28] D. I. Anderson, R. A. Magill, and H. Sekiya, "Motor learning as a function of KR schedule and characteristics of task-intrinsic feedback," Journal of motor behavior, vol. 33, pp. 59-66, 2001.

[29] V.K. Viswanathan, and M. Calhoun, "Improving Student Learning Experience in an Engineering Graphics Classroom through the Mastery Approach," ASEE Annual Conference, Seattle, WA, 2015. 